\title{
PERBANDINGAN EFEKTIVITAS AROMATERAPI LAVENDER DENGAN SENAM PILATES TERHADAP PENURUNAN NYERI HAID PADA REMAJA PUTRI
}

\section{COMPARISON OF THE EFFECTIVENESS OF LAVENDER AROMATHERAPY WITH PILATES GYMNASTICS AGAINST DECREASED MENSTRUAL PAIN IN YOUNG WOMEN}

\author{
Dhea Fernindi ${ }^{1}$, M. Ridwan ${ }^{2}$ \\ ${ }^{1,2}$ Poltekkes Tanjung Karang Program Studi Kebidanan Metro \\ Email: ridwan@poltekkes-tjk.ac.id
}

\begin{abstract}
ABSTRAK
Angka kejadian dismenorea pada remaja putri di Pondok Pesantren Daarul A'mal Kota Metro yaitu sebesar 63,3\%, sedangkan di Pondok Pesantren Roudlatul Qur'an Kota Metro lebih tinggi yaitu sebesar 71,6\%. Dampak yang terjadi akibat dismenorea ini menyebabkan siswi tidak dapat mengikuti proses pembelajaran di kelas, tidak masuk sekolah dan bahkan mengganggu aktivitas mereka sehari-hari. Salah satu upaya yang dapat dilakukan untuk mengatasi nyeri haid (dismenorea) adalah dengan menggunakan terapi non farmakologi berupa pemberian aromaterapi lavender secara inhalasi dan melakukan senam pilates yang diberikan pada dua kleompok yang terpisah dan perlakuakn yang berbeda. Tujuan penelitian ini adalah untuk mengetahui efektifitas antara pemberian aromaterapi lavender dengan senam pilates terhadap penurunan nyeri haid pada remaja putri di Pondok Pesantren Roudlatul Qur'an Kota Metro. Jenis penelitian yang digunakan adalah quasi experiment dengan pendekatan Pretest-posttest group design tanpa group kontrol. Teknik pengambilan sampel yang digunakan adalah teknik purposive sampling dengan besar sampel sebanyak 50 orang siswi terdiri dari 25 orang untuk pemberian aromaterapi lavender dan 25 orang untuk melakukan senam pilates. Analisis yang digunakan dalam penelitian ini adalah analisis univariat dan analisis bivariat adalah dengan uji Mann Whitney. Hasil analisis univariat menunjukkan bahwa sebelum diberikan aromaterapi lavender rerata nyeri haid pada remaja putri adalah 5,08 dan setelah diberikan aromaterapi lavender rerata nyeri haid pada remaja putri adalah 1,36, sedangkan sebelum melakukan senam pilates rerata nyeri haid pada remaja putri adalah 5,68 dan setelah melakukan senam pilates rerata nyeri haid pada remaja putri adalah 1,92, dengan $p$ value 0,000 yang menunjukkan bahwa senam pilates lebih efektif dalam penurunan nyeri haid pada remaja putri yang berarti ada perbedaan efektifitas antara pemberian aromaterapi lavender dengan senam pilates terhadap penurunan nyeri haid pada remaja putri.
\end{abstract}

Kata Kunci : Aromaterapi Lavender, Senam Pilates, Nyeri Haid.

\begin{abstract}
The incidence of dysmenorrhoea in young women in Pondok Pesantren Daarul A'mal Kota Metro is 63.3\%, while in Pondok Pesantren Roudlatul Qur'an Metro City is higher by 71.6\%. The impact of dysmenorrhoea causes students to be unable to follow the learning process in class, not attend school and even interfere with their daily activities. One of the efforts that can be done to overcome menstrual pain (dysmenorrhoea) is to use non-pharmacological therapy in the form of inhalation lavender aromatherapy and pilates gymnastics given to two separate kleompok and different behaviors. The purpose of this study is to find out the effectiveness between the administration of lavender aromatherapy and pilates gymnastics against the reduction of menstrual pain in young women in Pondok Pesantren Roudlatul Qur'an Kota Metro. The type of research used is quasi experiment with Pretest-posttest group design approach without group control. The sampling technique used is purposive sampling technique with a large sample of 50 students consisting of 25 people for the administration of lavender aromatherapy and 25 people to do pilates gymnastics. The analysis used in this study is univariate analysis and bivariate analysis is with Mann Whitney test. The results of univariate analysis showed that before being given lavender aromatherapy the average menstrual pain in young women was 5.08 and after being given lavender aromatherapy the average menstrual pain in young women was 1.36 , whereas before doing pilates gymnastics the average menstrual pain in young women is 5.68 and after doing pilates gymnastics the average menstrual pain in young women is 1.92 , with a $\mathrm{p}$ value of 0.000 which indicates that pilates gymnastics is more effective in decreasing menstrual pain in young women which means there is a difference in effectiveness between giving lavender aromatherapy with pilates gymnastics to decrease menstrual pain in young women
\end{abstract}

Keyword : Lavender Aromatherapy, Pilates Gymnastics, Menstrual Pain. 


\section{PENDAHULUAN}

Hampir sebagian wanita mengalami rasa tidak enak pada perut bagian bawah saat menstruasi berupa kram ringan yang berakibat pada terganggunya aktivitas dan tugas sehari-hari pada wanita. Dalam hal ini, dismenorea dibagi menjadi dua diantaranya dismenorea primer adalah nyeri haid yang terjadi tanpa disertai dengan kelainan anatomis dari alat kelamin, dan dismenorea sekunder adalah nyeri haid yang berhubungan dengan kelainan anatomis pada alat kelamin yang kemungkinan disertai infeksi seperti endometriosis, mioma uteri, polip endometrial dan polip. ${ }^{1}$

Penyebab utama nyeri haid dikarenakan adanya penekanan pada kanalis servikalis (leher rahim) yang muncul pada hari pertama atau menjelang hari pertama menstruasi. ${ }^{2}$ Nyeri haid bisa diatasi dengan terapi farmakologis yang bisa dilakukan dengan memberikan penderita nyeri haid obat analgetik, terapi hormonal, obat nonsteroid prostaglandin, dan dilatasi kanalis servikalis.

Terapi non farmakologi diantaranya dengan memberikan kompres hangat, terapi musik klasik mozart dan senam pilates yang memiliki gerakan inti lebih banyak untuk melatih kekuatan otot-otot perut, punggung bagian bawah dan panggul, dimana otot-otot yang dilatih tidak hanya otot bagian luar, namun juga otot bagian dalam ${ }^{4}$.

Aromaterapi merupakan salah satu tehnik pengobatan atau perawatan yang menggunakan bau-bauan yang berasal dari minyak esensial aromaterapi. Relaksasi dengan menghirup aromaterapi lavender yang memiliki kandungan utama linalyl asetat yang berfungsi untuk mengendorkan dan melemaskan sistem kerja saraf dan otot yang mengalami ketegangan sedangkan linalool berperan sebagai relaksasi dan sedatif sehingga dapat menurunkan nyeri saat haid atau dismenorea. Aromaterapi yang digunakan secara inhalasi atau dihirup kemudian akan masuk ke sistem limbic karena mencium baunya. Pada saat kita menghirup suatu aroma, komponen kimianya akan masuk ke bulbus olfactory, kemudian ke limbic sistem pada otak, hal ini akan merangsang memori dan juga respon emosional. Kemudian hipotalamus yang berperan sebagai relay dan regulator yang akan memunculkan pesan-pesan yang harus disampaikan ke bagian otak serta bagian tubuh lain. Saat pesan diterima, kemudian akan diubah menjadi tindakan yang berupa pelepasan senyawa elektrokimia yang akan menyebabkan euphoria, relaks dan sedatif ${ }^{5}$.

Senam Pilates merupakan suatu teknik yang bertujuan untuk penguatan, penguluran dan fleksibilitas dalam pemeliharaan bentuk tubuh dengan abdomen (perut) sebagai pusat kekuatan yang bekerja selama senam pilates dilakukan ${ }^{4}$. Pilates memiliki pola gerakan dasar yang menitikberatkan pada gerakan-gerakan otot panggul dan otot perut dimana gerakan dasar ini seringkali dikenal sebagai stable core, karena otot panggul dan perut dianggap sebagai otototot yang memiliki kestabilan paling tinggi ${ }^{6}$.

Berdasarkan hasil penelitian menunjukkan bahwa mayoritas responden mengalami nyeri haid dengan skala nyeri yaitu 4.56 dengan standar deviasi 1,45 dan rata-rata skala nyeri setelah diberikan aromaterapi lavender yaitu 1,50 dengan standar deviasi 1,15. Sehingga dapat disimpulkan bahwa nilai $\mathrm{p}=0,000$ $(\mathrm{p}<0,05)$ berarti ada pengaruh pemberian aromaterapi lavender terhadap penurunan nyeri haid dan merupakan salah satu alternatif yang menjanjikan pada penanganan dismenorea secara non-farmakologi $i^{7}$.

Penelitian yang dilakukan Araujo, dkk, menunjukkan bahwa nyeri menstruasi sebelum melakukan pilates adalah $7.89 \pm 1,96$ dan setelah melakukan pilates $2.56 \pm 0,56$ dengan $\mathrm{p}<0,001$. 
Dengan demikian Pilates sebagai latihan fisik telah dipercaya untuk mengurangi nyeri saat menstruasi dan menunjukkan bahwa Pilates adalah salah satu alternatif yang menjanjikan pada penanganan dismenorea secara nonfarmakologi ${ }^{4}$.

Berdasar hasil survey pendahuluan pada remaja putri kelas XI di Pondok Pesantren Roudlatul Qur'an Kota Metro sebanyak 71,6\% (58) dari 81 orang mengalami dismenorea, sedangkan di Pondok Pesantren Darul A'mal Kota Metro sebesar 63,3\% (38) dari 60 orang mengalami dismenorea.Tujuan penelitian ini adalah untuk mengetahui efektivitas antara pemberian aromaterapi lavender dengan senam pilates terhadap penurunan nyeri haid pada remaja putri.

\section{METODE}

Penelitian ini merupakan penelitian Quasy Eksperimen dengan pendekatan pretest-posttest group design tanpa group kontrol yang terdiri dari 25 orang untuk pemberian aromaterapi lavender dan 25 orang untuk melakukan senam pilates. Responden diberi perlakuan berupa pemberian aromaterapi lavender selama 10 menit yang dilakukan pada hari pertama dan kedua nyeri haid dan senam pilates dengan 5 macam gerakan yang dilakukan selama \pm 30 menit dengan frekuensi 5-10 kali hitungan pada tiap gerakan, dilakukan 3 kali sehari selama satu kali siklus menstruasi dan dilakukan 1 hari sebelum menstruasi.

Populasi dalam penelitian ini adalah 57 remaja putri di Pondok Pesantren Roudlatul Qur'an Kota Metro. Besar sampel dalam penelitian ini dihitung dengan menggunakan rumus besar sampel untuk data numerik terhadap rerata dua populasi independen ${ }^{8}$, dengan rumus:

$$
\mathrm{n}=2\left[\frac{\mathrm{Z} \alpha+\mathrm{Z} \beta) \mathrm{S}}{X 1-X 2}\right]^{2}
$$

Berdasarkan rumus tersebut maka jumlah sampel yang digunakan dalam penelitian ini adalah sebesar 37,32. Untuk mengantisipasi adanya drop out dan sebagai cadangan penelitian sebnyak 25\%, sehingga jumlah sampel total 50 orang yang dikelompokkan menjadi 25 orang pemberian aromaterapi lavender dan 25 orang untuk melakukan senam pilates. Teknik pengambilan sampel yang akan digunakan adalah teknik purposive sampling yang memenuhi kriteria inklusi yaitu siswi kelas XI SMA Pondok Pesantren Roudlatul Qur'an yang sudah haid dan mengalami keluhan berupa nyeri saat haid berupa nyeri ringan dan sedang, memiliki siklus haid teratur dan bersedia untuk mengikuti prosedur penelitian. Sedangkan kriteria eksklusi adalah siswi yang menggunakan terapi farmakologi berupa obat-obatan analgetik dalam menangani nyeri haid, yang mengalami tingkat nyeri haid berat dengan intensitas nyeri 10 dan yang menderita penyakit atau kelainan ginekologi. Penelitian menggunakan kuesioner untuk mengukur nyeri menggunakan Wong Baker Facial Grammace Scale (Judha, 2012: $38)^{2)}$ dan lembar checklist untuk observasi tindakan pemberian aromaterapi lavender dan senam pilates. Penelitian dilakukan pada santri putri kelas XI Pondok Pesantren Roudlatul Qur'an Kota Metro Bulan Februari - Mei 2019 dengan alasan tingginya kejadian dismenorea sebesar $71,6 \%$ dari 81 orang siswi kelas XI.

\section{HASIL}

Tabel 1

Rerata nyeri haid siswi sebelum dan sesudah pemberian aromaterapi lavender

\begin{tabular}{ccccc}
\hline Nyeri Haid & Mean & SD & 95\% CI & Selisih \\
\hline Sebelum & 5,08 & 1,29 & $5,31-6,09$ & 3,72 \\
Sesudah & 1,36 & 1,14 & $3,07-3,72$ & \\
\hline
\end{tabular}

Tabel 1, diketahui dari 25 orang rerata intensitas nyeri haid siswi sebelum pemberian aromaterapi 
lavender sebesar 5,08 (nyeri sedang), 95\% CI: 5,31-6,09 dengan standar deviasi 1,29. Intensitas nyeri terendah 3 dan tertinggi 8 . Sedangkan rerata intensitas nyeri haid siswi sesudah pemberian aromaterapi lavender sebesar 1,36 (Nyeri Ringan), 95\% CI: 3,07-3,72 dengan standar deviasi 1,14. Intensitas nyeri terendah 1 dan tertinggi 6 (Wong Baker Facial Grammace Scale). Diperoleh rerata perbedaan antara pengukuran sebelum dan sesudah pemberian aromaterapi lavender sebesar 3,72.

Tabel 2

\section{Rerata nyeri haid siswi sebelum dan sesudah} dilakukan Senam Pilates

\begin{tabular}{ccccc}
\hline Nyeri Haid & Mean & SD & 95\% CI & Selisih \\
\hline Sebelum & 5,68 & 1,31 & $5,36-6,17$ & \\
Sesudah & 1,92 & 1,15 & $3,09-3,85$ & \\
\hline
\end{tabular}

Tabel 2, dari 25 orang diketahui rerata intensitas nyeri haid siswi sebelum dilakukan senam pilates sebesar 5,68 (nyeri sedang), 95\% CI: 5,36-6,17 dengan standar deviasi 1,31. Intensitas nyeri terendah 4 dan tertinggi 9 . Sedangkan rerata intensitas nyeri haid siswi sesudah dilakukan senam pilates sebesar 1,92 (Nyeri Ringan), 95\% CI: 3,09-3,85 dengan standar deviasi 1,15. Intensitas nyeri terendah 1 dan tertinggi 8 (Wong Baker Facial Grammace Scale). Diperoleh rerata perbedaan antara pengukuran sebelum dan sesudah dilakukan senam pilates sebesar 3,76 .

Tabel 3

Efektivitas Pemberian Aromaterapi Lavender dan Senam Pilates Terhadap Penurunan Nyeri Haid

\begin{tabular}{|c|c|c|c|c|c|c|}
\hline \multirow{2}{*}{ Variabel } & \multirow{2}{*}{$\mathbf{N}$} & \multirow{2}{*}{$\begin{array}{l}\text { Mean } \\
\text { Rank }\end{array}$} & \multirow{2}{*}{ Selisih } & \multicolumn{2}{|c|}{$95 \% \mathrm{CI}$} & \multirow{2}{*}{$\begin{array}{c}\mathbf{P} \\
\text { value }\end{array}$} \\
\hline & & & & Lower & Upper & \\
\hline $\begin{array}{l}\text { Aromaterapi } \\
\text { Lavender }\end{array}$ & 25 & 25,94 & \multirow{2}{*}{0,04} & \multirow{2}{*}{3,397} & \multirow{2}{*}{4,123} & \multirow{2}{*}{0,000} \\
\hline $\begin{array}{l}\text { Senam } \\
\text { Pilates }\end{array}$ & 25 & 25.06 & & & & \\
\hline
\end{tabular}

Tabel 3 dapat diketahui bahwa dari hasil perhitungan menggunakan uji Mann Whitney (karena data tidak terdistribusi normal) didapatkan Mean Rank aromaterapi lavender sebesar 25,94, dan senam pilates sebesar 25,06, perbedaan selisih dari 2 perlakuan yaitu 0,04 dengan $P$ value $0,000<0,05$. Maka dapat disimpulkan bahwa Ha diterima dan $\mathrm{H0}$ ditolak yang berarti senam pilates lebih efektif dalam penurunan nyeri haid pada remaja putri.

\section{PEMBAHASAN}

\section{Rerata Nyeri Haid Sebelum dan Sesudah Pemberian Aromaterapi Lavender}

Hasil penelitian menunjukkan bahwa perbedaan intensitas rerata nyeri haid antara pengukuran sebelum dan sesudah pemberian aromaterapi lavender adalah 3,72. Terjadinya nyeri haid diakibatkan karena pada saat otot rahim berkontraksi, mereka membatasi jumlah pasokan darah ke jaringan dari endometrium yang menyebabkan jaringan menjadi rusak dan mati. Kontraksi berlebihan yang terjadi dalam secara terus-menerus akan memeras jaringan keluar dan menyebabkan kurangnya oksigen pada jaringan yang berakibat akan munculnya rasa sakit atau kram selama menstruasi ${ }^{1}$. Selain itu berdasarkan karakteristik responden didapatkan bahwa rerata usia menarche siswi adalah pada usia 13-14 tahun merupakan periode pertama menarche biasanya menstruasi terjadi secara tidak teratur dan menyebabkan beberapa dari remaja putri mengalami nyeri saat haid.

\section{Rerata Nyeri Haid Sebelum dan Sesudah dilakukan senam pilates}

Hasil penelitian menunjukkan bahwa rerata perbedaan intensitas nyeri haid antara pengukuran sebelum dan sesudah dilakukan senam pilates sebesar 3,76. Nyeri haid yang dirasakan oleh remaja putri disebabkan oleh prostaglandin yang memiliki peran dalam mengatur proses yang terjadi dalam tubuh salah 
satunya seperti kontraksi uterus. Jika kadar prostaglandin berlebih saat menstruasi, maka kontraksi uterus akan bertambah sehingga mengakibatkan terjadinya nyeri pada saat haid ${ }^{11}$.

\section{Efektivitas Aromaterapi Lavender dengan Senam Pilates Terhadap Penurunan Nyeri Haid}

Berdasarkan uji Mann Whitney didapatkan Mean Rank aromaterapi lavender sebesar 25,94, dan senam pilates sebesar 25,06, perbedaan selisih dari 2 perlakuan yaitu 0,04 dengan $P$ value 0,000 $<0,05$. Maka dapat disimpulkan bahwa $\mathrm{Ha}$ diterima dan H0 ditolak yang berarti senam pilates lebih efektif dalam penurunan nyeri haid pada remaja putri di Pondok Pesantren Roudlatul Qur'an Kota Metro.

Senam pilates lebih efektif dalam menurunkan nyeri haid kemungkinan karena gerakan dalam senam pilates hanya seperti gerakan peregangan pada saat olahraga dan tidak memerlukan keahlian atau keterampilan yang khusus untuk melakukannya sehingga senam pilates dapat dilakukan oleh remaja putri kapan saja di dalam kamar tidur maupun diluar ruangan. Sementara pemberian aromaterapi lavender perlu pengondisikan ruangan yang memungkinkan uap yang dihirup maksimal sehingga memberi efek mengurangi sampai menurunkan nyeri haid.

Remaja putri yang mengalami nyeri haid diharapkan dapat melakukan senam pilates sebagai salah satu terapi komplementer nonfarmakologi untuk mengurangi nyeri haid (dismenorea). Melakukan Senam piletes saat nyeri haid yang dirasakan remaja putri juga sebagai usaha meniadakan ketergantungan pada obat-obatan kimiawi. Istirahat yang cukup dan makanan yang seimbang juga membantu mempercepat mengurangi nyeri haid selain senam pilates.

\section{KESIMPULAN}

Rerata intensitas nyeri haid siswi sebelum pemberian aromaterapi lavender sebesar 5,08 (nyeri sedang) dan rerata intensitas nyeri haid siswi sesudah pemberian aromaterapi lavender sebesar 1,36 (Nyeri Ringan).

Rerata intensitas nyeri haid siswi sebelum melakukan senam pilates sebesar 5,68 (nyeri sedang) dan rerata intensitas nyeri haid siswi sesudah melakukan senam pilates sebesar 1,92 (Nyeri Ringan).

Hasil uji statistik rerata perbedaan selisih dari pemberian aromaterapi dan senam pilates yaitu 0,04 dan diperoleh $P$ value $0,000<0,05$. Kesimpulnya bahwa senam pilates lebih efektif dalam penurunan nyeri haid dibanding aromaterapi lavender pada remaja putri di Pondok Pesantren Roudlatul Qur'an Kota Metro.

\section{SARAN}

Remaja putri yang mengalami nyeri haid diharapkan dapat melakukan senam pilates sebagai salah satu terapi komplementer nonfarmakologi untuk mengurangi nyeri haid (dismenorea). Kelemahan penelitian ini mengingat sasaran penelitian merupakan santriwati dengan aktivitas pesantren yang telah terjadwal sehingga saat intervensi dilakukan tidak disertai istirahat yang cukup. Hal ini dapat mempengaruhi hasil intervesi yang diberikan. Sedangkan kekuatan penelitian ini adalah sasaran penelitian terkonsentrasi pada satu lokasi sehingga memudahkan intervensi dan monitoring.

\section{DAFTAR PUSTAKA}

1. Manuaba, dkk. 2009. Memahami Kesehatan Reproduksi Wanita, Penerbit Buku Kedokteran EGC, Jakarta. 
2. Judha, dkk. 2012. Teori Pengukuran Nyeri Dan Nyeri Persalinan, Yogyakarta, Nuha Medika. 139 halaman.

3. Prawirohardjo, S. 2009. Ilmu Kandungan Edisi 2, Yayasan Bina Pustaka, Jakarta.

4. De Araujo, L.M. 2012. Pain Improvement In Women With Primary Dysmenorrhea Treated With Pilates, Center Of United Teaching Of Teresina (CUET), Teresina PI.

5. Dewi AP, I.P. 2011. Aromaterapi Lavender Sebagai Media Relaksasi, Bagian Farmasi Fakultas Kedokteran Universitas Udayana.

6. Husin, F. 2014. Asuhan Kehamilan Berdasarkan Bukti. Jakarta, Sagung Seto.

7. Pustikawaty, R. 2016. Pengaruh Aromaterapi Lavender Terhadap Skala Nyeri Haid Siswi Kelas X Sekolah Menengah Atas Negeri 1 Sungai Ambawang Kabupaten Kubu Raya, Universitas Tanjungpura, Pontianak (Diakses: 23 Januari 2019).

8. Sastroasmoro, S; Sofyan I. 2014. DasarDasar Metodologi Penelitian Klinis. Jakarta: Sagung Seto.

9. Maharani. Yuliana Vivian, Fatmawati. Ery, Widyaningrum. Rahmah. 2016. Pengaruh Aromaterapi Bunga Lavender (Lavendula Angustifolia) Terhadap Intensitas Nyeri (Dismenore) Pada Mahasiswi STIKES Madani Yogyakarta, Jurnal Kesehatan Madani Medika, Vol.7 No.1 uni 2016. Hal: 43-49 (Diakses: 23 Januari 2019).

10. Ulsafitri, Y. 2017. Pengaruh Exercise Pilates Dengan Penurunan Nyeri Haid Primer Pada Mahasiswa DIII Kebidanan Tingkat I STIKER Yarsi Bukittinggi, Sumatera Barat (Diakses: 23 Januari 2019).

11. Kusmiran, E. 2011. Kesehatan Reproduksi Remaja Dan Wanita, Jakarta, Salemba Medika. 